\title{
CONTRIBUTION OF INTELLIGENT ADVISER MODUle Proposals in BIONIC ASSEMBLy SYSTEM
}

\author{
Damir Haskovic, Branko Katalinic, Ilija Zec \& Ilya Kukushkin
}
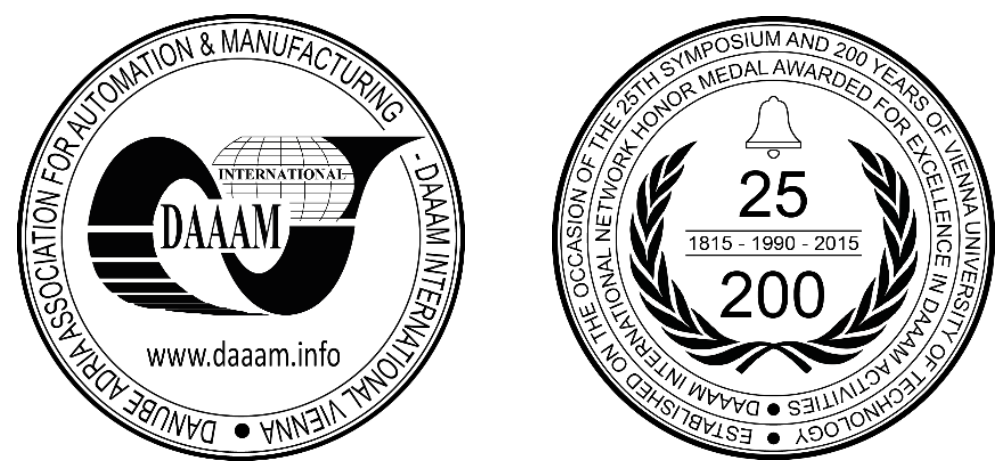

This Publication has to be referred as: Haskovic, D[amir]; Katalinic, B[ranko]; Zec, I[lija] \& Kukushkin, I[lya] (2018). Contribution of Intelligent Adviser Module Proposals in Bionic Assembly System, Proceedings of the 29th DAAAM International Symposium, pp.1299-1305, B. Katalinic (Ed.), Published by DAAAM International, ISBN 978-3-90273420-4, ISSN 1726-9679, Vienna, Austria

DOI: $10.2507 / 29$ th.daaam.proceedings. 187

\begin{abstract}
The research presented in this paper focuses on the investigation of working scenarios and efficiency of next generation of modern assembly systems. These systems are known as Bionic Assembly System (BAS). BAS is a human centric system which promotes the integration of workers in the working process. Human tasks in the control system are performed by the system operator. He makes the final decisions. BAS efficiency strongly depends on his ability to make high quality decisions and / or in shorter time. During normal working mode, the need for system operator decisions is relatively low. During disturbances and transition mode, the need for system operator decisions is high and crucial. He must make decisions under stress and following restrictions: large amounts of data, incomplete information and time limitation. To support the system operator during his decision making, a tool named Intelligent Adviser Module (IAM) is introduced. The investigation of contribution of IAM proposals on the quality and time of decisions is made. The results show that the quality of decisions is higher, and / or time is shorter, especially during: solving of conflict situations, solving of complex situations, solving of non-standard situations and support of less experienced system operators.
\end{abstract}

Keywords: Intelligent Adviser Module; Bionic Assembly System, efficiency, hybrid control structure, proposals

\section{Introduction}

The growing impact of science and technology causes our world to constantly change. A perfect example of this is globalization and its impact on the production industry [1]. It has introduced big changes through high competitiveness and a dynamic environment. To stay competitive, modern assembly systems need to respond to these challenges through adaptability, efficiency and robustness.

Bionic Assembly System (BAS) represents a next generation of hybrid assembly systems [2]. It is a part of a natural development within Industry 4.0 [3][4]. It is based on biologically inspired principles of self-organisation, reduced centralized control, networking between units and natural parallel distribution of processes. BAS control system combines two principles: subordination from factory level to BAS control structure, and self-organization at the shop floor level. This concept is here called hybrid control structure [5]. 
BAS is a complex production system. Here, the role of the system operator is crucial. He must be able to make decisions with high quality and / or in shorter time with fragmented and incomplete information about the actual system states and its components. BAS functionality and high work efficiency depend on this ability [6].

The main sources of information for the system operator are coming from: human communication, control system feedback, shop floor feedback [7]. The main data stream is between the control system and the shop floor. Data stream from the control system to the shop floor are commands. Data stream from the shop floor to the control system are responses. Only a small part of this data stream is presented to the system operator. It gives data about actual system states at the system operator's disposal.

Quality of decisions and time needed to reach them by the system operator are variable, due to his human nature (concertation, stress, fatigue and other) [8]. Because of this, the quality of decisions can be lower and the time needed to reach them can be longer than objectively possible. This can be improved, by developing a decision support tool for the system operator [9]. This tool here is named as the Intelligent Adviser Module (IAM). As an integral part of BAS control system, the IAM should take into consideration actual system states, past system states, external data from manuals and other documentation, human experts and past system behaviour [10].

Work of the IAM should be based on:

- Actual system state data from the interface between the control and the controlled system.

- Digitally recorded data from a significant period of past working time.

- Extraction of expert knowledge and expertise from humans directly involved with the system.

- Forecast of the execution of working scenarios for a short time horizon.

- Accumulated "situation-decision-results" cases from the past.

- Constant generation of IAM proposals according to the situation. IAM proposals should always be available. The final decision is made exclusively by the system operator. He decides if he will accept, partially accept or ignore the proposals.

The IAM proposals answer to the question: What to do here and now? The IAM is continuously updating its proposals. They are not mandatory for the system operator. IAM is an integral part of the BAS control system. As a result of this integration, IAM should be able to learn and to improve the accuracy of its proposals over time. Such proposals are a result of the IAM's ability to incorporate actual system states, predefined domain specific knowledge, human expertise and system specific experiences [10].

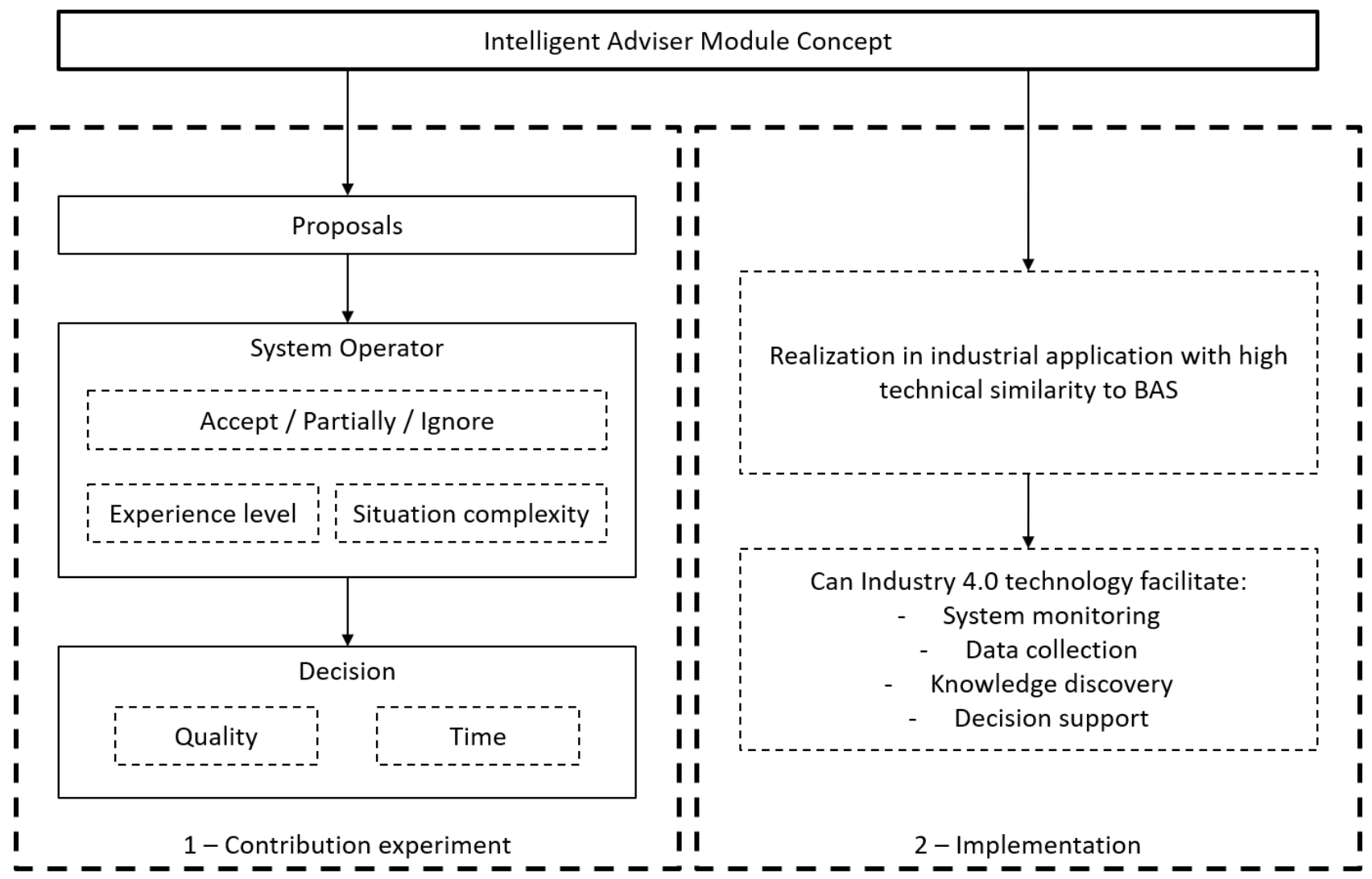

Fig. 1. Field of investigation 
However, as shown in Fig. 1., system operator is the final decision maker. He alone decides if he will accept, partially accept or ignore the IAM proposals. System operator experience in contrast to situation complexity has a direct influence on the quality of decision and time needed to reach them [11]. Additionally, BAS and IAM are in their concept stage. For this reason, real-world performance data is unavailable. Therefore, the main aim of this paper is to investigate the contribution of IAM proposals on the quality and time of decisions. This is achieved with an experiment, in which the interaction between multiple system operators and the IAM will be examined in various case studies. The IAM is simulated and is assumed to be fully functional.

The paper starts by describing the main IAM principle of operation, followed by the experiment set-up. The last part of the paper presents the analysis of the results. The paper concludes with key investigation points and presents future research which focuses on the IAM realization in industrial application with high technical similarity with BAS as shown in Fig. 1. [12]

\section{IAM principle of operation}

The system operator needs to ensure an uninterrupted execution of working scenarios by making final decisions. However, he has limited ability to make such decisions in good time. Good time means that the shop floor elements do not wait for his decision during the executions of BAS working scenarios. Generally, if the system operator considers a problem to be simple or that he has enough time to solve it, he would not use the adviser function. Instead, he would directly apply the solution he finds acceptable. On the other hand, if he considers a problem to be complex, or that he does not have enough time or knowledge, he has the adviser function at his disposal as shown in Fig. 2.

The adviser function presents a dialog manager which serves to exchange information with the system operator and to define a problem. This is realised as a series of questions on which the system operator answers. Such an information exchange can be executed as a conversation. This makes it more natural and intuitive for the system operator. Many different data collection methods can be utilized. This includes Boolean (Yes / No) questions, input/output values (time, speed, percentage...), multiple choice, etc. [13].

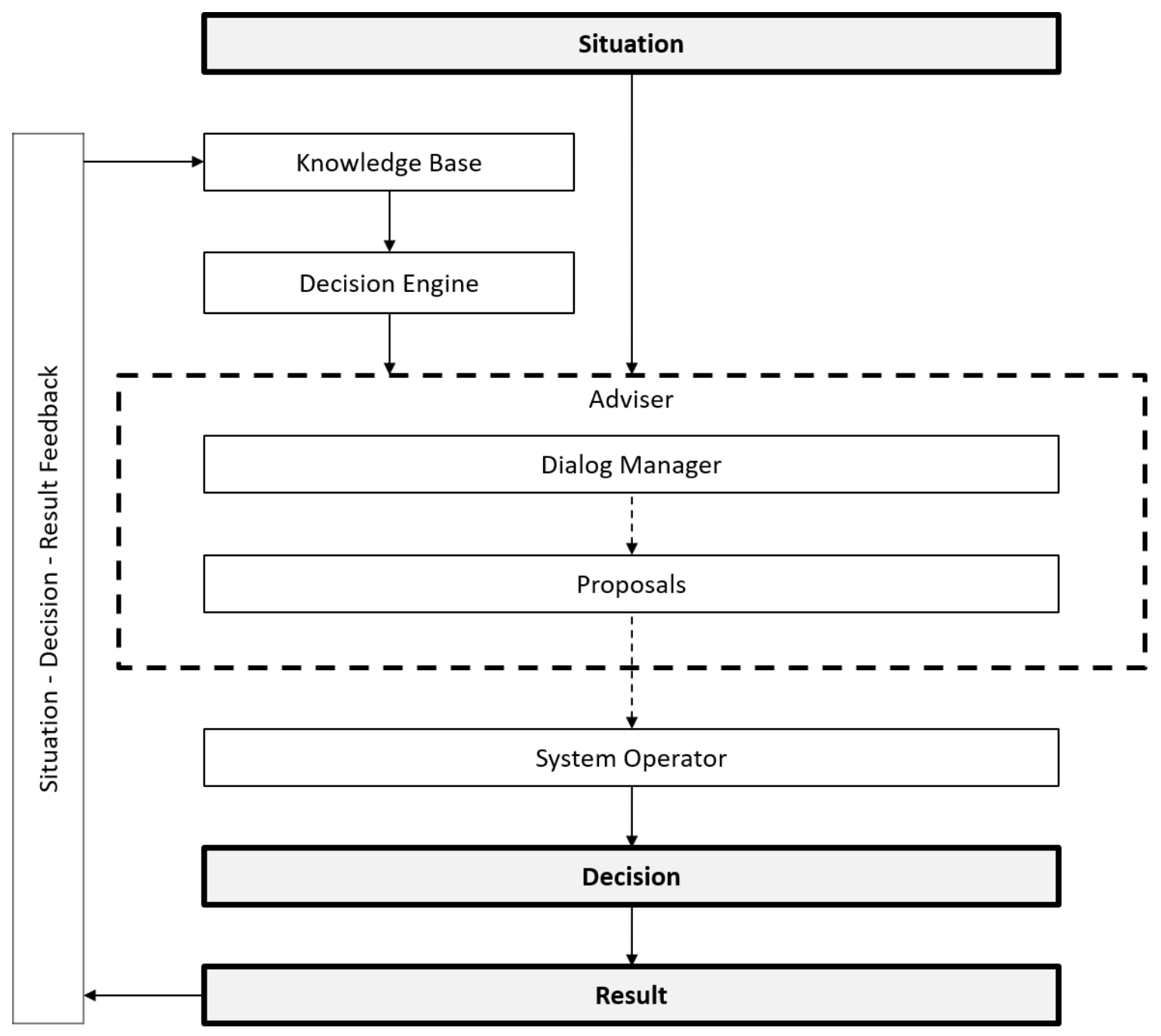

Fig. 2. IAM: Situation - Decision - Result Feedback 
Such inputs from the dialog manager are called problem descriptors. The IAM completes its function based on its knowledge base (KB), decision engine and these newly acquired descriptors. The results of this procedure are proposals. The system operator decides if he will accept, inspect or reject them. If possible, it is recommended that the system operator gives feedback about his choice right afterwards. This data is recorded for future reference. This way the IAM learns and expands its KB. All this information can be useful if a similar problem repeats.

After each decision, the results are recorded back to the KB as a situation - decision - result (SDR) feedback:

- A situation represents the circumstances in which the adviser is used. It includes the problem type and description, where the problem originates, when it occurred, list of all the shop floor elements involved.

- Decision represents the final solution which was applied by the system operator and why. After the exchange of information using the dialog manager, he alone decides what to do.

- Result represents the applied solution, when it was applied and if the system operator's decision was positive, neutral or negative.

\section{Experiment set-up}

Before the experiment is set up, there are a number of assumptions which will be incorporated into the experiment. These include:

- IAM is fully functional and implemented in the BAS control structure

- IAM is operating according to expected real life performance

- There are multiple workers performing the duty of the system operator

- System operators do not have the same level of experience

The human subjects need to perform a 2D error compensation" task by moving the randomly generated red square which represents an error to the zero position which represents the solution and is located at the intersection of the $\mathrm{x}$ and $\mathrm{y}$ axis. The movement is completed using the keyboard arrow keys. Level of disturbance [14] is an additional variable which can be adjusted according to the needed case study.

There are 3 levels of disturbance:

- Level D1 represents normal working scenarios. Here, all arrow keys have the same movement as displayed on the keyboard. For example, if the subject wishes to move the square to diagonally lower-right, he/she would press the down and right keys.

- Level D2 represents transition mode. Here, only two arrow keys remain the same. The other two have their function randomly reversed. For example, if the subject wishes to move diagonally upper-left, he/she would press the up and right keys.

- Level D3 represents disturbance mode. Here all arrow keys have a different function randomly assigned to them. For example, if the subject wishes to move diagonally lower/left, he/she would press the up and right keys.

The higher the level of disturbance, the more the subject will have to use his experience and "relearn" the arrow key functions. This will have an affect on time and quality to solve the problem. To help the subjects to minimize such affect, the proposals in the IAM window are shown in the form of "Press Key 1 x times \& Key 2 x times". That means that the subjects will need to press exactly that combination of keys that many times even if it is not intuitive according to what they see.

The experiment is organised through following case studies as shown in Fig 3.:

- Case A: Simple problems without IAM (200 data entries) - Subjects perform error compensation tasks with constant disturbance level D1 and no assistance from the IAM.

- Case B: Simple problems with IAM (200 data entries) - Subjects perform error compensation tasks with constant disturbance level D1 and with assistance from the IAM.

- Case C: Complex problems without IAM (200 data entries) - Subjects perform error compensation tasks with random disturbance levels D1, D2 and D3 and no assistance from the IAM.

- Case D: Complex problems with IAM - Individual approach (200 data entries) - Subjects perform error compensation tasks with random disturbance levels D1, D2 and D3 with assistance from the IAM. Subjects are instructed to try and reach a balance between quality decisions and good time during their problem solving and interaction with the IAM.

- Case E: Complex problems with IAM - Wait for advice (200 data entries) - Subjects perform error compensation tasks with random disturbance levels D1, D2 and D3 with assistance from the IAM. Subjects are instructed to exclusively wait for an advice from the IAM during their problem solving.

- Case F: Complex problems with IAM - Adjusted for balance (200 data entries) - Subjects perform error compensation tasks with random disturbance levels D1, D2 and D3 with assistance from the IAM. Additional case study adjusted for balance between higher quality and good time. 
The experiment is held in the following two runs:

- Run 1 - 10 human subjects marked as (S1.1 - S1.10) perform the following case studies A, B, C, D, E, F.

- Run 2 - additional 15 human subjects marked as (S2.1 - S2.15) perform the following case studies A, B, C, D, E, $\mathrm{F}$.

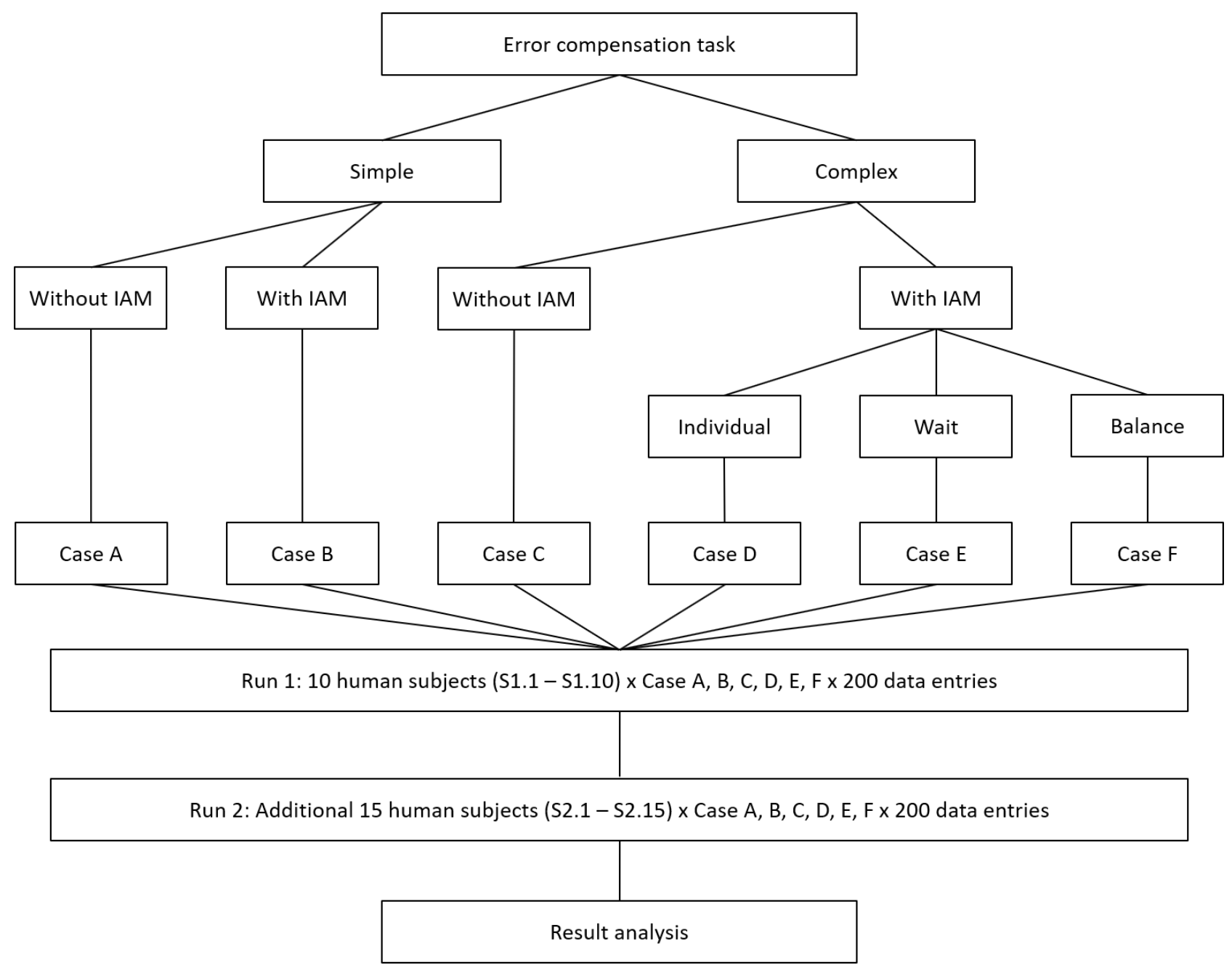

Fig. 3. Experiment case studies for the "2D error compensation" task

\section{Analysis of results}

A comparison of cases A, without and case B, with the IAM, during normal working mode is shown in Fig. 4. Overall, there was a slight increase of the quality of decisions with the assistance from the IAM in both runs. In the first run there was an increase of $0.71 \%$ and in the second run of $0.56 \%$. On the other hand, time needed to reach a decision with the IAM was improved by $5 \%$ in run 1 and in the second run by $3 \%$.

A comparison of cases C, D and E which cover random working, transition and disturbance modes is shown in Fig. 5. When comparing average values from cases $C$, without IAM and case $D$, with IAM, there was an increase of the quality of decisions with the IAM in both runs in the range from $4 \%$ till $8 \%$. With time needed to reach a decision, there were slight inconsistencies caused by individual system operator performances.

The first run resulted in an average longer time of $3 \%$ with IAM. However, in the second run there was an improvement of 5\% shorter time. Additionally, when comparing case C to control case E, with IAM, but where the system operator has to strictly wait and accept the advice, there was an expected increase of quality of decision of $24 \%$ in both runs. However, this causes $17 \%$ time increase. 


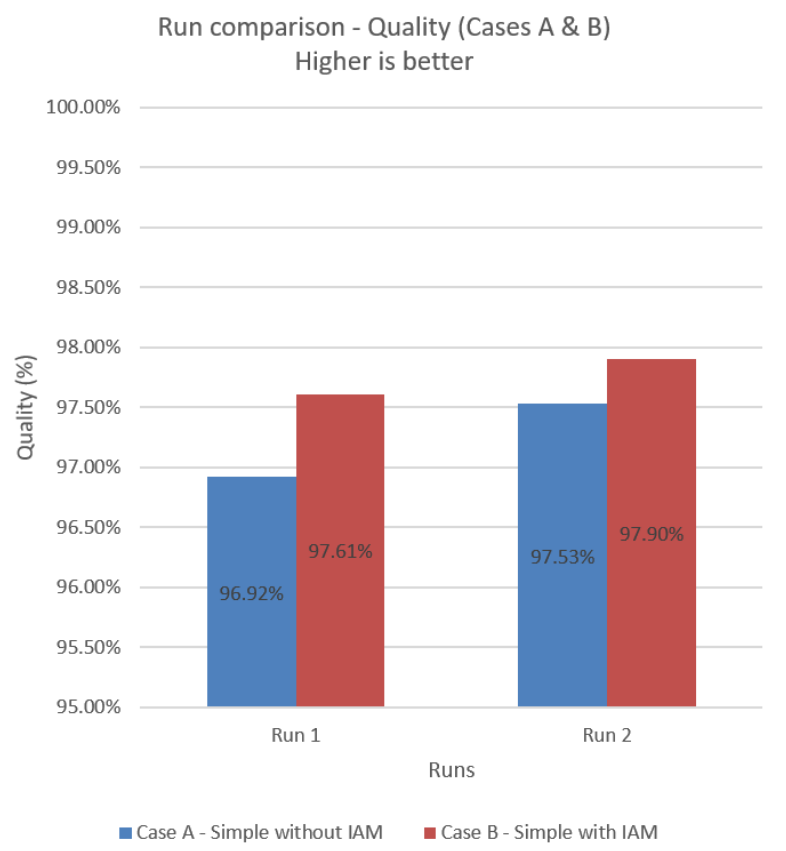

Quality improvement from $0.56 \%-0.71 \%$

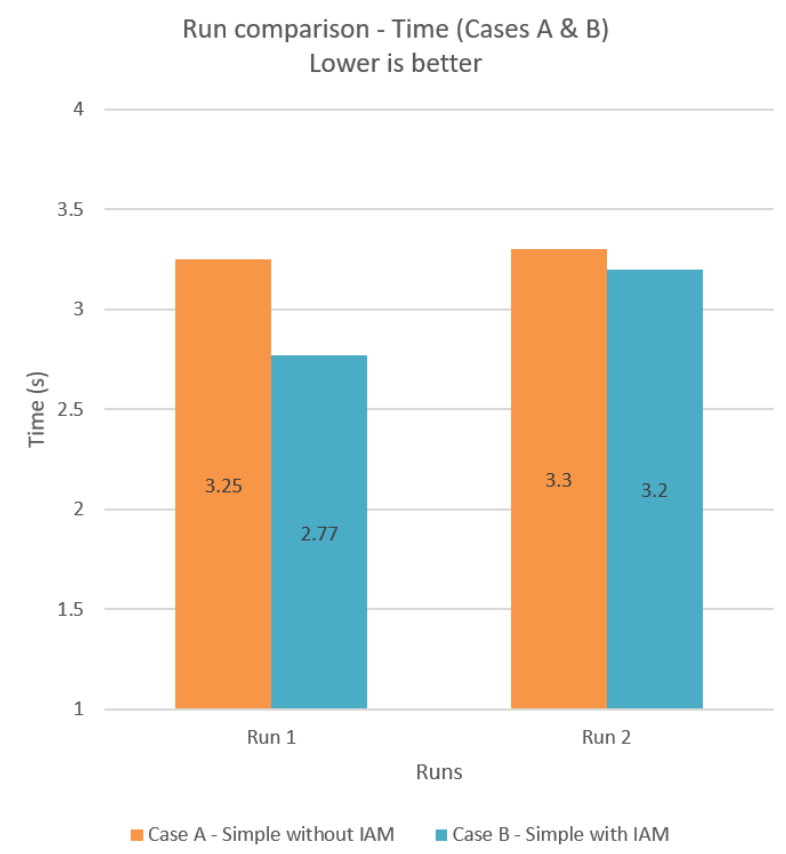

Time improvement from $3 \%-5 \%$

Fig. 3. Comparison of cases A, without and case B, with the IAM, during normal working mode

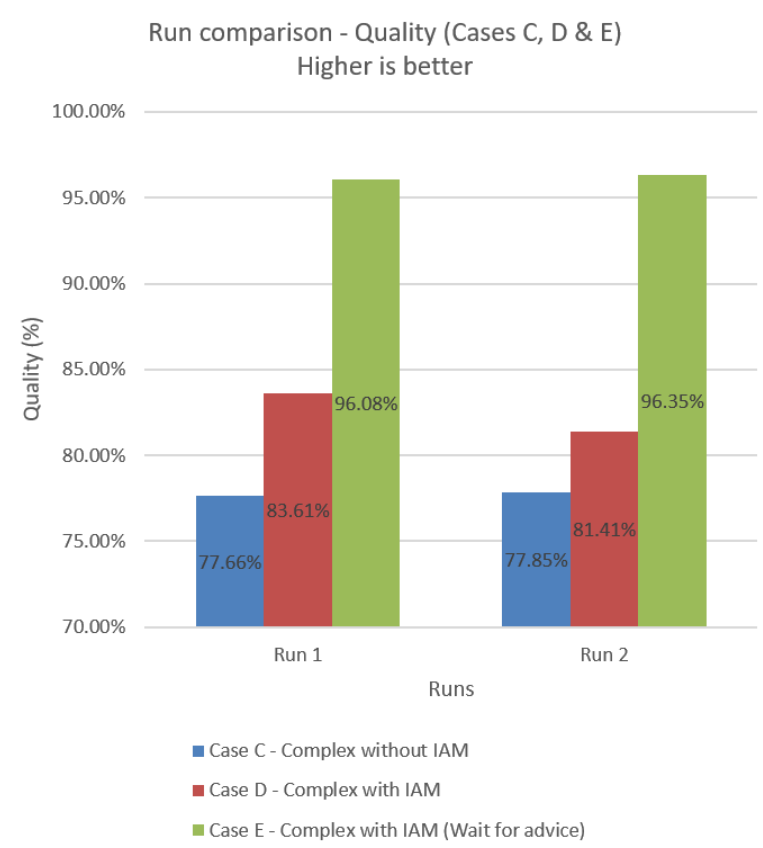

With IAM: Quality improvement from $4 \%-8 \%$ Wait for advice: Quality improvement around $24 \%$

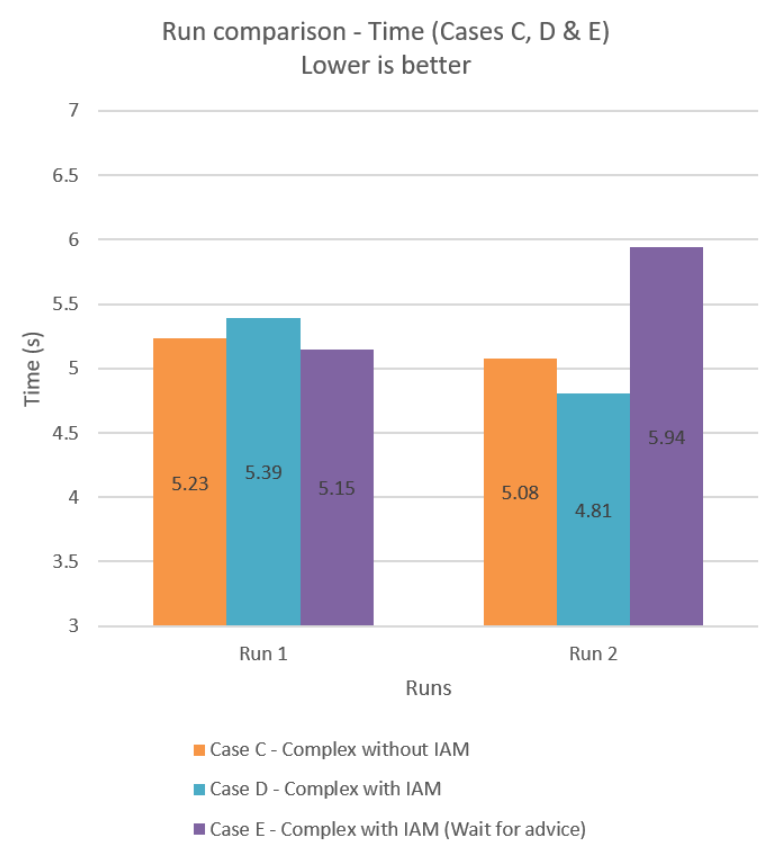

With IAM: Time improvement around 5\% Wait for advice: Time increase around $17 \%$

Fig. 4. Comparison of cases $\mathrm{C}, \mathrm{D}$ and $\mathrm{E}$ which cover random working, transition and disturbance modes

\section{Conclusion}

The research presented in this paper focused on the investigation of working scenarios and efficiency of next generation of modern assembly systems. These systems are known as BAS. The main focus was the investigation of contribution of IAM proposals on the quality and time of decisions made by the system operator. 
The main results of the investigation are that the by introducing the IAM, quality of decisions is higher, and / or time is shorter, especially during: solving of conflict, complex, non-standard situations and during support of less experienced system operators. IAM continuously generates proposals which answer on the question: what is right to do in this situation here and now and is comparable to a navigation system: it offers proposals of ways based on input data: actual position, present time and the target. Proposal are continuously generated with any change of input data.

This represents a promising direction of development of future modern assembly systems. One possible direction of further development is the verification of IAM concept in an industrial application with high technical similarity with BAS.

\section{Acknowledgments}

This paper would not be possible without the mentorship and encouragement from Univ. Prof. Dr.sc. Dr.mult.h.c. Prof.h.c. Branko Katalinic.

\section{References}

[1] Henderson, J. (2002). Globalisation of high technology production. Routledge.

[2] Katalinic, B., Visekruna, V. \& Kordic, V. (2002). Bionic Assembly Systems: Design and Scheduling of Next Generation of Self-organising Complex Flexible Assembly System in CIM environment, Proceedings of the 35th CIRP-International Seminar on Manufacturing Systems, 12-15 May 2002, Seoul, Korea

[3] Takakuwa, S.; Veza, I. \& Celar, S. (2018). "Industry 4.0" in Europe and East Asia, Proceedings of the 29th DAAAM International Symposium, pp.0061-0069, B. Katalinic (Ed.), Published by DAAAM International, ISBN 978-3902734-20-4, ISSN 1726-9679, Vienna, Austria, DOI: 10.2507/29th.daaam.proceedings.009

[4] Medojevic, M.; Diaz Villar, P.; Cosic, I.; Rikalovic, A.; Sremcev, N. \& Lazarevic, M. (2018). Energy Management in Industry 4.0 Ecosystem: a Review on Possibilities and Concerns, Proceedings of the 29th DAAAM International Symposium, pp.0674-0680, B. Katalinic (Ed.), Published by DAAAM International, ISBN 978-3-902734-20-4, ISSN 1726-9679, Vienna, Austria, DOI: 10.2507/29th.daaam.proceedings.097

[5] Katalinic, B., Kukushkin, I. K., Cesarec, P., \& Kettler, R. (2012). Hybrid control structure and scheduling of bionic assembly system. In Proc. 8th International Conference of DAAAM Baltic, Industrial Engineering (pp. 483-489). Tallinn, Estonia

[6] Haskovic, D., Katalinic, B. \& Kukushkin, I. (2015). Role of the Adviser Module in the Hybrid Assembly Subordinating Control Structure, Procedia Engineering, Volume 100, 2015, Pages 1706-1713, ISSN 1877-7058, http://dx.doi.org/10.1016/j.proeng.2015.01.546

[7] Haskovic, D.; Katalinic, B.; Zec, I.; Kukushkin, I. \& Zavrazhina, A. (2017). Intelligent Adviser Module: Proposals and Adaptive Learning Capabilities, Proceedings of the 28th DAAAM International Symposium, pp.1191-1196, B. Katalinic (Ed.), Published by DAAAM International, ISBN 978-3-902734-11-2, ISSN 1726-9679, Vienna, Austria, DOI: $10.2507 / 28$ th.daaam.proceedings. 165

[8] Getty, David J., et al. (1995). System operator response to warnings of danger: A laboratory investigation of the effects of the predictive value of a warning on human response time, Journal of Experimental Psychology: Applied 1.1 (1995): 19

[9] Haskovic, D., Katalinic, B., Kildibekov, A. \& Kukushkin, I. (2016). Intelligent Adviser Module for Bionic Assembly Control System: Functions and Structure Concept, Proceedings of the 26th DAAAM International Symposium, pp.1158-1165, B. Katalinic (Ed.), Published by DAAAM International, ISBN 978-3-902734-07-5, ISSN 1726-9679, Vienna, Austria

[10] Haskovic, D., Katalinic, B., Zec, I., Kukushkin, I. \& Zavrazhina, A. (2016). Structure and Working Modes of the Intelligent Adviser Module, Proceedings of the 27th DAAAM International Symposium, pp.0866-0875, B. Katalinic (Ed.), Published by DAAAM International, ISBN 978-3-902734-08-2, ISSN 1726-9679, Vienna, Austria, DOI: 10.2507/27th.daaam.proceedings. 125

[11] Aronson, J. E., Liang, T. P., \& Turban, E. (2005). Decision support systems and intelligent systems. Pearson Prentice-Hall

[12] Pryanichnikov, V., Aryskin, A., Eprikov, S., Kirsanov K., Khelemendik, R., Ksenzenko, A., Prysev, E. \& Travushkin, A. (2017). Technology of Multi-Agent Control for Industrial Automation with Logical Processing of Contradictions, Proceedings of the 28th DAAAM International Symposium, pp.1202-1207, B. Katalinic (Ed.), Published by DAAAM International, ISBN 978-3-902734-11-2, ISSN 1726-9679, Vienna, Austria, DOI: 10.2507/28th.daaam.proceedings. 167

[13] Haskovic, D. (2018). Working Scenarios of Hybrid Self-Organizing Assembly System. Wien, Techn. Univ., Dissertation

[14] Deming, W. E. \& Edwards, D. W. (1982). Quality, productivity, and competitive position (Vol. 183). Cambridge, MA: Massachusetts Institute of Technology, Center for advanced engineering study 